\title{
The Human as Double Bind: Sylvia Wynter and the Genre of "Man"
}

\author{
Emily Anne Parker \\ TOWSON UNIVERSITY
}

\begin{abstract}
Sylvia Wynter's philosophy of sociogenesis is an implicit response to a double bind instituted by conceiving of humanity in what she calls generic terms. Either one is human and measured by a morphology that privileges an implicit whiteness, masculinity, cis-ness, hetero-ness, symmetry, and ability, or one is a biological organism without necessarily having recourse to the recognition humans share with each other. Wynter addresses this double bind in arguing first that what is political has in fact always had ecological implications. Bodies denied in politics are in fact of great consequence for politics. This implicit morphology of the genre "Man" has always included the presumption that "Man" can and does act unilaterally. And second, Wynter addresses the double bind in her reading of Fanonian sociogenesis. There is no generic body, as Wynter reads Fanon. The way in which a body is regarded, given the "sociogenic principles" of a political context, is an indistinguishably biological-political matter.
\end{abstract}

KEYwords: Sylvia Wynter, the body, Renaissance, sociogenesis, Frantz Fanon

Sylvia Wynter, novelist, dramatist, cultural critic, and philosopher, has called for a new poetics that "will have to take as its referent subject (in the place of our present referent of the bourgeois mode of the subject and its conception of the individual), that of the concrete individual human subject" 
(Wynter and McKittrick 2015, 47). By "referent subject" Wynter means a shared sense, poetic in nature, that can nevertheless exclude many who are also expected to live it. Man, Wynter argues, as a referent subject first appeared in the Italian Renaissance. As Walter Mignolo (2015, 109) has argued, this way of representing an individual is made visual in Leonardo da Vinci's Vitruvian Man, a man of perfect symmetry and supposedly ideal form. Wynter suggests that the Vitruvian Man has become the medical chart of "the skeletal or muscular system" hanging in countless medical offices. This mode of knowing is then synonymous with the "referent subject," the presumed author of the Anthropocene, an epoch in which it is possible to chart a changing planet but for which a poetics is lacking for explicitly articulating what referent subject or morphology could collaborate to make such changes possible. There is clearly a referent subject, but it is an implicit one who only acquires words for himself from his Others: blackness, darkness, blindness, penetrability, impregnability, dependence (Wynter I995, 42). Man is supposedly not these things. For Wynter, this becoming Man in both modes-the Vitruvian Man and the medical-natural organism-defines itself as "the human" precisely by, as I will discuss, distinguishing among "bodiments" that are intuitively humanity-in-negativerelation. Such intuition is owed to the salience of Man. Mignolo has also suggested that in decoupling Man from humanity, Wynter's aim "is not to find the true and objective definition of 'what is Human,' but to show that such projects are filled with an imperial bend, a will to objectivity and truth" (20I5, IIO). In the claim with which I began, in which Wynter argues that the "concrete individual" must become a "referent subject," Wynter is articulating a poetics, one that does, I agree with Mignolo, reject "the will to objectivity and truth" of "the human" (Mignolo 2015, IIO). And yet how can a concrete individual become a referent subject, something that is by definition collective? In making this suggestion, Wynter is implicitly responding to a current double bind set in motion by the very idea of "the human" as defined by European modernity.

Wynter undermines in an unprecedented way an implicit distinction between the political and the ecological that shows itself if one compares, for example, the work of Karen Barad and Saidiya Hartman. While Barad, in Meeting the Universe Halfway: Quantum Physics and the Entanglement of Matter and Meaning (2007), writes of the powers of agential materiality without attention to the role of the rejections of human blackness, darkness, blindness, penetrability, impregnability, and dependence considered 
synonymous with inert matter, Hartman, in Scenes of Subjection: Terror, Slavery, and Self-Making in Nineteenth-Century America (I997), writes precisely of the rejections of blackness without attention to the role of what Barad calls a more-than-human agential materiality. (The awkwardness of my own use of the word human here is precisely that in which I am interested.) What I am trying to point to is the division of a modern terrain that Barad and Hartman might be read together as representing. Both works are crucial to my own understanding, but both leave out essential pieces in which the other is, I think, fundamentally interested. What is the connection between the denial of the agencies of matter and ongoing colonization?

By modern terrain I mean "modernity" according to Bruno Latour and "Manichaeanism" according to Frantz Fanon: ${ }^{2}$ what is political never ceases to be ecological, and yet the senses of the terms ecological and political almost always diverge sharply in the modern philosophical vocabulary and canon and human morphology. For Fanon this divide is owed to the conceptualization of a certain white man speaking a certain language and with a certain mythology as a morphology that characteristically attempts to distinguish itself from materialities. This is a specific culture that is intuitive and yet not consciously palpable to those who live it. It is marked by what Fanon (2004, 6-9) names Manichaeanism in The Wretched of the Earth. The world is divided into humans and nonhumans. For Fanon, whiteness/language/religion in this way constitute a morphology in denial of its own contingent bodiment and bent on the active denunciation of any other than gives the lie to this denial. Sylvia Wynter expands this approach: a certain Man, constituted by, in terms only more recently emerging for naming Man, cis/white/masculinity/ability/sexuality/class/nationality/ geography, is produced by a denial of its own specific bodiment, something that this body hides from itself. It denies its status as a "concrete individual," as "flesh-and-blood" body, precisely by contrasting itself with other bodies and ignoring and silencing those who would depart from this morphology. Such denial creates and relies upon a political realm thus constructed upon the denial of that which modernity projects and partitions as bodily, and today there are words precisely for pointing to all that is left out of what is considered modern/political: the feminine, transness, blackness, dis/ability, queerness, nonbinariness. Such words are crucial, but they are produced by an implicit morphology that can continue to feel implicit, even when named as composed of cis/white/masculinity/ability/sexuality/class/nationality/ geography. Thus even individuals who know to check the box "white" on 
a demographic form are likely not able to appreciate consciously that they are in fact white and all that this means in their day-to-day life. Other features of this body—cisgender, language, nationality, ability—can likewise be understood on a factual or "biological" level and yet entirely unappreciated in moment-by-moment interactions precisely because they only have sense in being not-transgender, not-accented, not-("foreign"-)languaged, not-from-another-place, not-disabled. And yet without these contrasting bodies such an implicit morphology could not exist.

This implicit morphology gives rise to a double bind. "The human" and "the body" are expressions of a modern distinction between that which is political and human and transcending of the bodily (which is projected onto other bodies) and that which is precisely bodily and thus ecological. Because of this, clearly an ecological turn is necessary to counter the splitting of the political from the ecological. But to reunite the human and the ecological is for some bodies a doubling down on a violent equation that they have experienced all along, as they continue to serve as the negative of "the human." To talk about ecology without a questioning of this ultimate homogeneity of "the human" means leaving unquestioned the fact that many bodies are its negative referents. In this way ecological thinking can be a continuation of modern Manichaeanism. Then again, to speak in strictly political terms means of course ignoring all of that which modernity deems "ecological," and that includes unshared bodily experiences and needs for life that are indistinguishably biological-cultural. One needs to think ecologically, but this is politically problematic; one needs to think politically, but this is premised upon a variety of denials insofar as they conflict with the human. Either an ecology without the human or the human without ecology: neither option is acceptable, and yet both are necessary.

What I would like to offer is that Wynter's philosophy of sociogenesis, which articulates Man as a denial of bodiment, is an implicit response to this double bind. Sociogenesis as a figure defies this double bind in further undermining an already unstable ecological-political distinction. Sociogenesis offers a way of thinking about humanity not only "as praxis," as lived in a time and a place, but also as a very sensory encounter. In doing so, what Wynter names the genre of Man offers a philosophy of whiteness, not only as an ethno-race to which I belong but as an ecologically alienated, sense-denying way of life. I have in mind the work of Linda Martín Alcoff, who has argued that a philosophy of whiteness is necessary for political purposes, a making explicit and palpable, rather than denying any reality 
to whiteness, in the manner of "eliminativist" projects. I am interested in the fact that for Wynter, a philosophy of whiteness, as the crucial feature of the genre of Man, in fact its historically new religion, is necessary for purposes that are indistinguishably ecological and political. Man according to Wynter becomes a religion insofar as it takes the place of all-powerful agency previously held by God in the Western tradition.

In "I492: A New World View" Wynter writes that a new poetics is needed, one that understands human not in biocentric terms, terms that boil what human means down to a supposedly factual biomedical definition, but as a "sociogenic" form of belonging among nevertheless natural organisms whose more-than-conscious self-understanding is also inherently social. As Alexander Weheliye has explained, this is an appropriation of a claim in Frantz Fanon's introduction to Black Skin, White Masks: "Alongside phylogeny and ontogeny," Fanon writes, "there is also sociogeny" (2008, $\mathrm{xv}$ ). Fanon goes on in that book to articulate sociogeny as a critique of "the inadequacy of traditional psychoanalytic models in the analysis of racialized colonialism" (Weheliye 20I4, 25). For Fanon, sociogeny would seem to be a radical revision of psychoanalysis, of acquaintance with what Fanon (2004, $2 \mathrm{I} 6$ n. 35) calls in The Wretched of the Earth cortico-visceral habits. Sociogeny is thus a word in Fanon not for the elaboration of self-consciousnesses or pure unconsciousnesses but for more-than-conscious bodies in relation.

In "Towards the Sociogenic Principle: Fanon, Identity, the Puzzle of Conscious Experience, and What It Is Like to Be 'Black'” (2009, 32), Wynter understands the sociogenetic or sociogenic principle to be a collectively held sense of self that shapes each organism's development. Elsewhere she refers to cultures as "sociogenic modes" (2003, 28I), styles of sociogenesis of nevertheless distinct bodies and modes of living. What it is like to be human here is inherently plural: it consists in being a specific body amid the sociogenic principles available for that body. In "Towards the Sociogenic Principle" Wynter argues that this offers a response to David Chalmers's "puzzle of conscious experience," namely, "how 'a subjective experience could possibly arise from the neural processes in the brain,' as well as why all this processing has to be 'accompanied by an experienced inner life" (Wynter 2009, 3I). The puzzle of conscious experience in Chalmers is related to the fact that consciousness seems superfluous. For Chalmers humans do not seem to need consciousness at all. Wynter answers: how a body perceives itself in racial terms reliant on a comparison with other bodies matters fundamentally not only to a person's living but to the character 
of the life of the species. Here she discusses Frantz Fanon's experience as a child in Martinique of being told not to "act black" (Wynter 2009, 33). While still in the Caribbean it was an option: misbehaving carried a meaning that one could avoid attaching to oneself. As Wynter puts it, "Although Negroes, they could opt not to behave like one, thereby not falling entirely into non-being, the negation of being human" (2009, 33). Fanon realized, however, upon arriving in France that this nonbeing was the sensation of his body for white people. A certain negativity-in the sense of both a very political nothing and a nothing that is felt-was a feature of his body in this context, in comparison with bodies understood as white. It was thus no longer an option for him, amid this totalizing negativity-in-relation. And this sense of others of Fanon's own body, owed to Man as understood in negative comparison with Fanon's own body, becomes Fanon's lived experience.

Wynter notes that Fanon was interested in the possibility that such a psychic revelation was also a biochemical alteration. Suddenly appreciating one's physicality as inherently lacking could be not the cause of but itself the lived experience of a change in "body fluids" (Wynter 2009, 36). Psychic transformation, Fanon proposed, was a set of biological processes that could not, however, be explained solely by studying brain activities. The response to a variety of bodies that Man overdetermines can only be understood with reference to bodies. This is a rewriting of Sigmund Freud's rejection of what he called "academic medicine" in his I9I5-I7 introductory lectures to psychoanalysis. Freud writes: "I must remark that I know nothing that could be of less interest to me for the psychological understanding of anxiety than a knowledge of the path of the nerves along which its excitations pass" (1966, 489). The point-for Freud and for Fanon-is not that what we call a brain is irrelevant, though they disagree as to how it is relevant. For Fanon, the corollary of his experience of sensing and being sensed, as a larger circuit, a larger "brain" perhaps, resides elsewhere than in Fanon himself: it resides in the fears of the white people he encounters, for example, on the quotidian train ride he has made famous. This story is not one of brains interacting; it is a story of bodies, which of course include what are called "brains."

Such fears and angers inspired by intuitions about what is human, experiences of being sensed, Wynter places at the heart of what it is like to be human. Wynter's interest does not so much seem to be in the fact that Fanon's was a transcultural event, of arrival in a new psychic milieu, though that was the condition for Fanon's earliest attempts to articulate 
sociogenesis. Rather, she is interested in the fact that this transition was instituted by bodies collectively inventing form for themselves against the bodies of others. Humans, it seems, must collectively create forms. However, the relations of each body to such a more or less shared form are not themselves uniform. In an interview with Katherine McKittrick, Wynter cites Derrida's "Ends of Man" in which Derrida questions the invocation of a European "we" (Wynter and McKittrick 2015, 23-24). Wynter cites Derrida's question: "But who, 'we'?" Wynter reads this as Derrida's own questioning of a certain genre or form of Man, a questioning of the universality of its own ends, specific to a form of humanity that has implicitly made a certain body synonymous with it. "Humanity" has not been conceived of as constituted by humans who must perceive each other in their very becoming human. As Wynter puts it: "French philosophers have assumed that, as middle-class philosophers, their referent-we is isomorphic with the referent-we ... in the horizon of humanity. I am saying here that the above is the single issue with which global warming and climate instability now confronts us and that we have to replace the ends of the referent-we of liberal monohumanist Man2 with the ecumenically human ends of the referent-we in the horizon of humanity. We have no choice" (Wynter and McKittrick 20I5, 24).

What I would like to suggest is that precisely in placing experiences of sensing and being sensed at the heart of what it is like to be human Wynter makes what is political indistinguishable from the ecological and in a way that avoids the double bind with which I began. First, she understands human relationality to have created an epoch that is coming to be understood as the Anthropocene. In her essay "I492: A New World View," Wynter suggests that the figure of sociogenesis is a way of uniting the perspectives of celebrants and dissidents of events for which 1492 is a symbol: "How . . . is the I492 event to be perceived? Should it be seen from the celebrant perspective-as a 'glorious achievement,' a 'heroic and daring deed' of discovery and exploration, a triumph for the Christian West that was to liberate the indigenous peoples from their Stone Age, deprived existence without the wheel? Or is it to be seen from the dissident perspective-as one of 'history's monumental crimes,' a brutal invasion and conquest that led to a degree of genocidal extinction and of still ongoing ecological disaster unprecedented in human history" (I995, 5)? Sociogenesis places these two all-too-human perspectives within a philosophy of "how the human represents to itself the life that it lives" (Wynter I995, 8). In other 
words, I492 might now be understood as natural organisms (Wynter's own terms) explaining themselves-and Others-to themselves in a way that is destructive and that cannot be parsed in either political or ecological terms alone. For Wynter, from the moment that a European "epochal shift" in self-understanding emerged —of the human as a natural organism-from the moment that Europeans began to contemplate themselves as earthly, a certain mode Man took the place of God, first in the Studia Humanitatis of fourteenth-century Europe. The Vitruvian Man is a visible expression of the beginnings of this shift toward what Wynter calls a "monohumanism." This Man became the more explicitly "biocentric" figure who, as Diana Coole and Samantha Frost put it in their introduction to New Materialisms: Ontology, Agency, and Politics, identified "as ontologically other than matter" (2010, 8). Coole and Frost very helpfully argue that in this period, humans were "variously ... portrayed as rational, self-aware, free, and self-moving agents" capable of manipulating and reconfiguring "matter on an unprecedented scale" (20I0, 8). There is a crucial political point missing in this formulation of the problem, and it is a point that Wynter makes. For Wynter, racialization is a necessary feature of this newly naturalized religion-ecology. It is not that humans are portrayed as the movers of matter; it is that a certain figure of the human, the Vitruvian Man, is synonymous with the orchestration of matter, and this human nevertheless has undeniable more-than-conscious relationships to other humans. Without what Walter Mignolo calls "the imperial diversity" of humanity both within and beyond Europe, Leonardo da Vinci's Vitruvian Man could not have emerged as a work of art or a figure for life itself. The Vitruvian Man does not yield this imperial diversity among humans and its denial of an entire earth of material agencies as a by-product; the Vitruvian Man is a visible picture of their denial. This is a religion merely "de-godded," as Wynter puts it, in which Man takes the place of an immaterial Christian God. The human as a now indispensable ontological term is thus constituted by an array of denials, voids, and nothingnesses in the political and is evocative of a realm now coming to be understood as ecological over which the political by definition exercises unilateral control.

It is not just that for Wynter humans' explanations of themselves to themselves in this way have created an epoch that is coming to be understood as the Anthropocene. It is also that in her work politics is understood to be indistinguishable from ecology while providing a new way of thinking about what human might mean-instead of Man as a universal that can be explicated as a positive science, each human body is in a relation to other 
human bodies in an irreducible and asymmetrical way. Politics for Wynter is a kind of ecology — of bodies among bodies-which takes place as part of a world of agencies that exceed each organism's self-understanding. And it is especially in this respect that she sidesteps the double bind with which I began. This double bind is one overdetermined by a modern affective constitution of the human: the human is a natural organism that is also master of the natural. He is and he is not bodily. He is in a very powerful relation to a "de-godded" earth, and a certain body came, during the Italian Renaissance, to take the place of God as epistemic and ontological keystone. Imperial diversity-or as Wynter names it "the Color (cum Colonial) Line" - becomes a naturalized religion, the hidden religion of a science. And so in political systems that take this keystone as their own, achieving something of an unfelt bodily status is paramount. Concerns that are overtly ecological or bodily are at best a liability. In "Unsettling the Coloniality of Being/Power/Truth/Freedom," Wynter argues that it is not possible to "unsettle" the "coloniality of power" that is responsible for the Anthropocene without attention to the relations among bodies that were essential to establishing modernity's culturally specific instrumental, naturalistic terms. This is, I think, what she means by "our uniquely human domain" $(2003,328)$ : it is not a new version of the human-as-homogeneousecological-pinnacle. Instead she is calling both for attention to the implicit relations that compose the human of the Anthropocene and for a way of thinking about a human plurality both necessary and denied.

Wynter has claimed that unlike bees, humans are not "purely biological eusocial systems" (Wynter and McKittrick 2015, 28). Humans are "hybrid": both "languaging and storytelling" living systems. It is not clear to me whether a distinction can really be made between what is biological and what is not, between "bios" and "mythos" (Wynter and McKittrick 20I5, 31). For Wynter the significance of this distinction is in the fact that "mythos" distinguishes what is human in her sense of this term from other forms of life. It seems to me that this is a resurgence of the modern distinction between ecology and politics in her work. But I do not think that this claim, that there is something about humanity that exceeds the biological, eliminates the power of her work as a paradigm for undermining the double bind that the human according to Italian Renaissance humanism sets up. As a critique of monohumanism, Wynter's work makes palpable the necessity of "the body" and "the human" for a problematic distinction between the ecological and the political. 


\section{NOTES}

I. I use bodiment instead of embodiment because I take the latter to be a hylomorphic term, em-bodiment, which suggests that something immaterial has passed into something material (em-). In this way the concept of embodiment problematically suggests that a body is divisible into agency as "form" and inertness as "matter."

2. As Latour has it in We Have Never Been Modern (I993, I0-I2), the word modern designates an effort to distinguish nature from culture that in fact scrambles them in a distinctively problematic way. The attempt to purge nature from culture and vice versa produces a culture of ecological devastation. See also Latour's The Politics of Nature: How to Bring the Sciences into Democracy (2004).

\section{WORKS CITED}

Barad, Karen. 2007. Meeting the Universe Halfway: Quantum Physics and the Entanglement of Matter and Meaning. Durham: Duke University Press.

Coole, Diana, and Samantha Frost. 2oro. New Materialisms: Ontology, Agency, and Politics. Durham: Duke University Press.

Fanon, Frantz. 2004. The Wretched of the Earth. Translated by Richard Philcox. New York: Grove Press.

Fanon, Frantz. 2008. Black Skin, White Masks. Translated by Richard Philcox. New York: Grove Press.

Freud, Sigmund. I966. Introductory Lectures on Psycho-analysis. Translated by James Strachey. New York: W. W. Norton.

Hartman, Saidiya V. I997. Scenes of Subjection: Terror, Slavery, and Self-Making in Nineteenth-Century America. New York: Oxford University Press.

Latour, Bruno. I993. We Have Never Been Modern. Translated by Catherine Porter. Cambridge: Harvard University Press.

Latour, Bruno. 2004. The Politics of Nature: How to Bring the Sciences into Democracy. Translated by Catherine Porter. Cambridge: Harvard University Press.

Mignolo, Walter D. 2015. “What Does It Mean to Be Human?” In Sylvia Wynter: On Being Human as Praxis, edited by Katherine McKittrick, Io6-23. Durham: Duke University Press.

Weheliye, Alexander G. 20I4. Habeas Viscus: Racializing Assemblages, Biopolitics, and Black Feminist Theories of the Human. Durham: Duke University Press.

Wynter, Sylvia. I995. “I492: A New World View." In Race, Discourse, and the Origin of the Americas: A New World View, edited by Vera Lawrence Hyatt and Rex Nettleford, 5-57. Washington, D.C.: Smithsonian Institution Press. Wynter, Sylvia. 2003. "Unsettling the Coloniality of Being/Power/Truth/

Freedom: Towards the Human, After Man, Its Overrepresentation-An Argument." New Centennial Review 3, no. 3 (Fall): 257-337. 
Wynter, Sylvia. 2009. “Towards the Sociogenic Principle: Fanon, Identity, the Puzzle of Conscious Experience, and What It Is Like to Be 'Black.'” In National Identities and Sociopolitical Changes in Latin America, edited by Mercedes F. Durán-Cogan and Antonio Gómez-Moriana, 30-66. New York: Routledge.

Wynter, Sylvia, and Katherine McKittrick. 2015. "Unparalleled Catastrophe for Our Species? Or, To Give Humanness a Different Future: Conversations." In Sylvia Wynter: On Being Human as Praxis, edited by Katherine McKittrick, 9-89. Durham: Duke University Press. 